\title{
Genetic background of the differences in timing of meiotic maturation in mouse oocytes: a study using recombinant inbred strains
}

\author{
Z. Polański \\ Department of Genetics and Evolution, Jagiellonian University, Kraków, Poland
}

\begin{abstract}
Recombinant inbred strains of mice derived from CBA and KE strains were used for studying the genetic background of the duration of the first meiotic cycle which differs in oocytes from progenitor strains. Oocytes were screened in vitro for the timing of germinal vesicle breakdown as well as for the timing of first polar body extrusion, and the approximate duration of the first meiotic M-phase was calculated. Although oocytes from progenitor strains did not differ in the duration of germinal vesicle breakdown, this characteristic segregated in recombinant strains showing involvement of at least two genes. Because of the similar duration of germinal vesicle breakdown in CBA and KE oocytes, the difference in timing of first polar body extrusion $(9 \mathrm{~h}$ and $12 \mathrm{~h}$ for CBA and KE, respectively) reflects the difference in the duration of the first meiotic $\mathrm{M}$-phase. The timing of germinal vesicle breakdown and the duration of $\mathrm{M}$-phase in recombinant strains were negatively correlated $(P<0.01)$; in general, the more time needed for breakdown of the germinal vesicle, the shorter the M-phase. The timing of first polar body extrusion varied among strains: in some it was similar to one of the parental strains; in others it was intermediate between the two, which again shows the involvement of at least two genes in the control of this character. The linkage analysis suggests that one of the putative genes influencing the timing of first polar body extrusion may be situated near the Gpi-1 locus on chromosome 7 , that is, in the region containing the locus for cyclin $\mathrm{E}$. The possible involvement of cyclin $E$ in the control of the timing of first meiosis in mouse oocytes is discussed.
\end{abstract}

\section{Introduction}

Mouse oocytes enter prophase of meiosis at the end of fetal life and become arrested in late prophase of the first meiotic division at the germinal vesicle (GV) stage. After a long arrest, fully grown oocytes start meiotic maturation (in response to gonadotrophins in vivo, and when released from antral follicles in vitro) which begins with the breakdown of the nuclear envelope (germinal vesicle breakdown, GVBD). The oocytes then progress through first metaphase, anaphase and telophase with the extrusion of the first polar body to the second metaphase, which is the final stage of meiotic maturation (Donahue, 1968). The oocytes remain at this stage until fertilization or parthenogenetic activation stimulate completion of meiosis and transition to the first mitotic cycle.

Mouse oocytes from the inbred strains CBA and KE differ greatly in the rate of meiotic maturation; in vivo the CBA oocytes extrude their first polar bodies at about $9 \mathrm{~h}$ of maturation, whereas the KE oocytes do so approximately 3-4 h later (Polański, 1986). Thus, oocytes from these two strains provide a good model for studying factors involved in the control of the first meiotic cycle.

In this study, mice from CBA, KE and recombinant inbred (RI) strains developed from these progenitor strains were used.

Received 12 July 1996.
Recombinant inbred strains, first developed and described by Bailey (1971), are especially useful for gene mapping, for analysis of pleiotropism, and for studying genetic and physiological correlations between characters, because each RI strain provides a repeatable, homozygous sample of a particular recombination (haplotype) of alleles that is different in the progenitor strains. In this study RI strains were used to investigate the genetic factors affecting the duration of first meiosis in mouse oocytes.

\section{Materials and Methods}

Mice

Adult female mice from two inbred strains, $\mathrm{CBA} / \mathrm{Kw}$ (referred to hereafter as CBA) and KE as well as from RI strains were used in this study. Five RI strains (EXCB 2, 3, 5, 6 and 10) were obtained from the original cross of $\mathrm{KE}$ females with $\mathrm{CBA}$ males, and five (CBXE 12, 13, 15, 17 and 20) from the reciprocal cross. The strain distribution pattern of the following genetic markers segregating in the RI strains is known: coat colour markers for the loci $a, b$ and $c$; histocompatibility locus $H-2$, and electrophoretic markers Idh-1, Upg-2, Svp-1, Car-2, Ce-2, Es-9, Gpi-1, Hbb, Ldr-1, Mod-1, Trf and Upg-1 (Rafinski et al., 1991; Krzanowska et al., 1994). Additional testing was also performed 
on nine incipient RI lines (CBXE 21-34) that had passed through only $13-15$ generations of inbreeding but were already homozygous for the loci that have been tested (a, Svp-1, b, Gpi-1, c, Hbb, Trf; Krzanowska et al., 1994; Idh-1, Car-2, Ce-2; J. Styrna, personal communication).

\section{The rate of oocyte maturation in vitro}

The oocytes at the GV stage were obtained by puncturing the antral follicles of dissected ovaries. The cumulus cells, if present, were removed by passing the oocytes through a narrow pipette. These operations were performed in Hepesbuffered M2 culture medium (Fulton and Whittingham, 1978) supplemented with $150 \mu \mathrm{g}$ dibutyryl cAMP (dbcAMP) $\mathrm{ml}^{-1}$ to prevent the oocytes from resuming maturation before being placed in the culture (Cho et al., 1974). After collection the oocytes were rinsed three times in M2 without dbcAMP and cultured in this medium (4-10 oocytes per drop of about $10 \mu \mathrm{l}$ ) at $37^{\circ} \mathrm{C}$ under paraffin oil for $16 \mathrm{~h}$ in air. The start of the culture was considered as the start of meiotic maturation. From the eighth hour of the culture, the oocytes were inspected every hour under the inverted microscope for the presence of the first polar body.

In separate experiments the timing of GVBD was tested. The oocytes, after isolation and being placed in the culture, were inspected for the disappearance of the germinal vesicle at I, 1.5, 2, 2.5, 3, 4 and $5 \mathrm{~h}$ of incubation.

During inspection the Petri dishes were placed on a warm $\left(37^{\circ} \mathrm{C}\right.$ ) transparent plate (Kitazato Supply Co., Ltd., Fujinomiya City, Japan) to prevent cooling of the culture.

\section{Statistical analyses}

Differences among groups were analysed by the ANOVA or Bonferroni test (Statistix Version 4.0, Analytical Software). A unit of measure within the group was the mean value obtained from all oocytes of an individual. $P<0.05$ was considered as statistically significant.

\section{Results}

During this study oocytes were cultured in vitro for 5 or $16 \mathrm{~h}$ to estimate the timing of GVBD and first polar body extrusion, respectively. The $16 \mathrm{~h}$ culture also allowed evaluation of the efficiency of in vitro maturation of oocytes in different strains (Table I). The frequency of GVBD and first polar body extrusion was similar in the two parental strains. Therefore, the data from $\mathrm{CBA}$ and $\mathrm{KE}$ females were pooled to evaluate the difference in efficiency of GVBD and first polar body extrusion between the parental and RI strains. Only one RI strain differed from the parental strains with respect to GVBD frequency (Table 1). More variance was observed regarding the efficiency of first polar body extrusion, where four phenotypes could be distinguished: efficient (frequency significantly higher than in progenitor strains; three RI strains), moderate (not differing from progenitors; most RI strains), low (significantly lower than in progenitors; one RI strain), and very low (significantly lower than in RI strain with low phenotype; one RI strain).
Table 1. The efficiency in progression of meiotic maturation of mouse oocytes from inbred strains, $\mathrm{CBA}$ and $\mathrm{KE}$, and recombinant inbred strains during $16 \mathrm{~h}$ of culture in vitro

\begin{tabular}{cccc}
\hline & $\begin{array}{c}\text { Number } \\
\text { of } \\
\text { females }\end{array}$ & $\begin{array}{c}\text { Oocytes } \\
\text { undergoing GVBD }\end{array}$ & $\begin{array}{c}\text { Oocytes extruding } \\
\text { first polar body }\end{array}$ \\
Strain & $(\%)$ & $(\%)$
\end{tabular}

\begin{tabular}{llll}
\hline CBA & 6 & $93.1 \pm 3.2$ & $81.9 \pm 3.5$ \\
KE & 6 & $96.1 \pm 1.3$ & $78.8 \pm 6.1$ \\
EXCB2 & 6 & $95.5 \pm 1.6$ & $82.2 \pm 3.7$ \\
EXCB3 & 2 & $89.1 \pm 0.9$ & $65.3 \pm 5.3$ \\
EXCB5 & 6 & $87.5 \pm 1.8^{*}$ & $26.8 \pm 3.1^{* *}$ \\
EXCB6 & 6 & $94.8 \pm 3.0$ & $83.6 \pm 4.2$ \\
EXCB10 & 6 & $97.0 \pm 3.0$ & $78.4 \pm 5.9$ \\
CBXE12 & 6 & $92.6 \pm 3.2$ & $65.5 \pm 8.4$ \\
CBXE13 & 6 & $93.0 \pm 2.8$ & $92.0 \pm 2.7^{* *}$ \\
CBXE15 & 6 & $98.2 \pm 1.2$ & $86.5 \pm 4.7$ \\
CBXE17 & 6 & $91.7 \pm 4.2$ & $51.3 \pm 5.4^{* *}$ \\
CBXE20 & 6 & $89.3 \pm 5.7$ & $66.8 \pm 7.6$ \\
CBXE21 & 6 & $97.0 \pm 3.0$ & $75.6 \pm 8.3$ \\
CBXE24 & 6 & $93.7 \pm 3.1$ & $88.4 \pm 4.0$ \\
CBXE26 & 6 & $90.4 \pm 2.2$ & $86.1 \pm 4.9$ \\
CBXE27 & 3 & 100 & $96.7 \pm 3.3^{* *}$ \\
CBXE28 & 5 & $95.3 \pm 2.9$ & $72.5 \pm 4.1$ \\
CBXE29 & 6 & $98.1 \pm 1.8$ & $81.0 \pm 6.7$ \\
CBXE32 & 5 & $91.2 \pm 4.1$ & $87.4 \pm 2.3$ \\
CBXE33 & 3 & 100 & $71.2 \pm 10.8$ \\
CBXE34 & 6 & 96.6 & $94.8 \pm 2.5^{* *}$ \\
\hline
\end{tabular}

Values expressed as means \pm sim.

a Calculated in relation to oocytes that had undergone germinal vesicle breakdown (GVBD).

*** Significantly different from pooled data from CBA and KE females (in relation to GVBD and extrusion of first polar body, respectively).

In some cases the cytokinesis resulted in the formation of two daughter cells of equal size rather than in that of the large MII oocyte and the first polar body. This phenomenon occurs very rarely at first meiotic division (Braden, 1957, cf. Tarkowski, 1971) and resembles the 'immediate cleavage' that occurs frequently in parthenogenetically activated eggs (Tarkowski, 1971; Kaufman, 1973). The frequency of equal division was low: in only five of 21 tested strains (CBA and KE included) did it exceed $10 \%$ of oocytes that had undergone first meiotic division, reaching the maximum (13.6\%) in the RI strain CBXE21. Within a given strain the timing of cytokinesis did not differ between oocytes cleaving equally and those extruding first polar bodies.

The mean time of GVBD did not differ significantly between progenitor strains $\mathrm{CBA}$ and $\mathrm{KE}(P>0.6)$, although it varied considerably among RI strains, ranging from $1.7 \mathrm{~h}$ to $2.8 \mathrm{~h}$ (Table 2). Analysis of the differences between progenitor strains (pooled data for CBA and KE) and RI strains revealed three phenotypes with respect to timing of GVBD; slow (one RI strain significantly slower than parental strains), moderate (RI strains not differing significantly from parental strains), and fast (four RI strains significantly faster than parental strains; Table 2).

The mean time of first polar body extrusion differed greatly between progenitor strains $(P<0.0001)$ : $9 \mathrm{~h}$ for $C B A$ and $12 \mathrm{~h}$ 
Table 2. The timing of germinal vesicle breakdown (GVBD) and first polar body (PB1) extrusion in mouse oocytes from inbred strains, $\mathrm{CBA}$ and $\mathrm{KE}$, and recombinant inbred strains

\begin{tabular}{|c|c|c|c|c|c|c|c|}
\hline \multirow[b]{3}{*}{ Strain } & \multicolumn{2}{|c|}{ GVBD } & \multicolumn{4}{|c|}{ PB1 extrusion } & \multirow{3}{*}{$\begin{array}{l}\text { Gpi-1 } \\
\text { form }\end{array}$} \\
\hline & \multirow{2}{*}{$\begin{array}{c}\text { Number } \\
\text { of } \\
\text { females }\end{array}$} & \multirow{2}{*}{$\begin{array}{l}\text { Time of } \\
\text { GVBD } \\
\text { (h) }\end{array}$} & \multirow{2}{*}{$\begin{array}{l}\text { Number } \\
\text { of } \\
\text { females }\end{array}$} & \multirow{2}{*}{$\begin{array}{l}\text { Time of PBI } \\
\text { extrusion } \\
\text { (h) }\end{array}$} & \multicolumn{2}{|c|}{ Phenotypes classified by } & \\
\hline & & & & & ANOVA & Bonferroni & \\
\hline CBA & 6 & $2.3 \pm 0.06$ & 6 & $9.0 \pm 0.34$ & $\mathrm{CBA}$ & $\mathrm{CBA}$ & $\mathrm{CBA}$ \\
\hline $\mathrm{KE}$ & 4 & $2.2 \pm 0.16$ & 6 & $12.0 \pm 0.24$ & $\mathrm{KE}$ & $\mathrm{KE}$ & KE \\
\hline CBXE12 & 4 & $2.2 \pm 0.20$ & 6 & $12.2 \pm 0.24$ & $\mathrm{KE}$ & $\mathrm{KE}$ & KE \\
\hline CBXE17 & 5 & $1.9 \pm 0.17^{*}$ & 6 & $11.7 \pm 0.32$ & $\mathrm{KE}$ & $\mathrm{KE}$ & KE \\
\hline EXCB10 & 3 & $1.7 \pm 0.10^{*}$ & 6 & $11.5 \pm 0.23$ & $\mathrm{KE}$ & $\mathrm{KE}$ & KE \\
\hline EXCB3 & \multicolumn{2}{|c|}{ not determined ${ }^{a}$} & 2 & $11.4 \pm 0.04$ & KE & $\mathrm{KE}$ & $\mathrm{KE}$ \\
\hline CBXE32 & 6 & $2.2 \pm 0.12$ & 5 & $11.0 \pm 0.25$ & I & $\mathrm{KE}$ & $\mathrm{KE}$ \\
\hline CBXE33 & 3 & $2.0 \pm 0.15$ & 3 & $10.9 \pm 0.24$ & I & I & CBA \\
\hline CBXE34 & 6 & $2.0 \pm 0.40$ & 6 & $10.8 \pm 0.39$ & I & KE & $\mathrm{KE}$ \\
\hline CBXE21 & 6 & $2.1 \pm 0.08$ & 6 & $10.7 \pm 0.25$ & I & $\mathrm{KE}$ & $\mathrm{KE}$ \\
\hline CBXE29 & 6 & $2.4 \pm 0.40$ & 6 & $10.7 \pm 0.53$ & l & $\mathrm{KE}$ & $\mathrm{KE}$ \\
\hline CBXE26 & 6 & $2.0 \pm 0.14$ & 6 & $10.6 \pm 0.38$ & I & I & $\mathrm{KE}$ \\
\hline CBXE24 & 5 & $2.2 \pm 0.27$ & 6 & $10.6 \pm 0.20$ & I & I & CBA \\
\hline EXCB2 & 4 & $2.2 \pm 0.08$ & 6 & $10.4 \pm 0.24$ & I & I & $\mathrm{KE}$ \\
\hline EXCB6 & 4 & $2.1 \pm 0.12$ & 6 & $10.4 \pm 0.28$ & I & I & KE \\
\hline CBXE28 & 5 & $1.9 \pm 0.12^{*}$ & 5 & $10.3 \pm 0.45$ & I & $\mathrm{CBA}$ & $\mathrm{CBA}$ \\
\hline EXCB5 & 3 & $2.5 \pm 0.08$ & 6 & $10.2 \pm 0.25$ & I & $\mathrm{CBA}^{\mathrm{b}}$ & $\mathrm{KE}$ \\
\hline CBXE2O & 4 & $2.1 \pm 0.14$ & 6 & $10.2 \pm 0.07$ & I & $\mathrm{CBA}$ & $\mathrm{CBA}$ \\
\hline CBXE15 & 4 & $2.1 \pm 0.09$ & 6 & $10.2 \pm 0.23$ & I & $\mathrm{CBA}$ & $\mathrm{CBA}$ \\
\hline CBXE27 & 3 & $1.9 \pm 0.14^{*}$ & 3 & $10.1 \pm 0.34$ & $\mathrm{CBA}^{\mathrm{b}}$ & I & KE \\
\hline CBXE13 & 3 & $2.8 \pm 0.17^{*}$ & 6 & $9.6 \pm 0.29$ & $\mathrm{CBA}$ & $\mathrm{CBA}$ & CBA \\
\hline
\end{tabular}

Values expressed as means \pm SEM.

${ }^{a}$ This strain died out in the course of experiments, before examination of the timing of GVBD

'Phenotype nonmatching to Gpi-1 form.

* Significantly different from pooled females from CBA and KE strains.

'I' denotes a phenotype intermediate between parental phenotypes (CBA or KE). Using ANOVA these strains differed significantly from both progenitor strains. Using the Bonferroni test these strains did not differ significantly from either progenitor strain.

for KE mice (Table 2). These values fit well to the rate of meiotic maturation that had been previously estimated in vivo: in females stimulated with exogenous gonadotrophins most oocytes extruded first polar body at about $9 \mathrm{~h}$ in CBA strain and 12-13 h in KE strain (Polański, 1986). This finding shows that removal of cumulus cells has little (if any) effect on the kinetics of oocyte maturation in culture. Each RI strain was individually compared with each of progenitor strains using ANOVA to evaluate the differences. In two RI strains (EXCB13, CBXE27) the timing of first polar body extrusion was similar to that of the CBA strain (difference statistically not significant), whereas in four lines (EXCB3, EXCB10, CBXE12, $X B X E 17)$ it was similar to the KE strain. In the remaining lines the mean time of first polar body extrusion was intermediate and differed significantly from both parental strains (Table 2).

To find possible linkages between the timing of first polar body extrusion and genetic markers determined earlier in our RI strains, their strain distribution patterns (SDPs) were compared. However, only six RI strains showed the phenotype of first polar body extrusion as $\mathrm{KE}$ or $\mathrm{CBA}$ when classified by ANOVA (Table 2); this is the minimum number of strains that allows testing of the significance of linkage (Silver, 1985). Therefore, the Bonferroni test of all comparisons among means, less sensitive in these conditions, was also used. When this test was used, 13 RI strains were classified as similar to one of the parental strains, thus revealing their phenotypes (Table 2).

In both cases of phenotype identification (ANOVA and Bonferroni) the SDP for timing of first polar body extrusion was most similar to the SDP of locus Gpi-1 (chromosome 7). In the first case (Table 2) in one of six RI strains these SDPs did not match (linkage not significant); in the second case the disconcordance was $1 / 13$ and gave statistically significant linkage $(P<0.01$; according to Silver, 1985$)$. This linkage would still be significant even when considering the RI strains CBXE27 and CBXE33 (with a small number of females tested; Table 2) as displaying parental phenotypes $C B A$ and $K E$, respectively $(3 / 15, P<0.05$; Silver, 1985). The value of linkage was calculated according to the formula

$$
r=R /(4-6 R)
$$

where $r$ is the map distance (multiplied by 100 this gives the value in centiMorgans; $\mathrm{cM}$ ) and $\mathrm{R}$ is the proportion of nonmatching RI strains (Taylor, 1981). This gives (considering the data obtained by using the Bonferroni test) a distance of $2.2 \mathrm{cM}$ between Gi-1 and a putative gene affecting the timing 


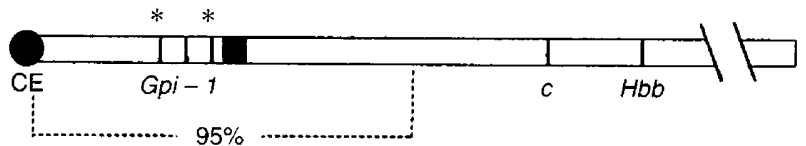

Fig. 1. Simplified map of chromosome 7. Asterisks mark two possible locations of a putative gene affecting the timing of first polar body extrusion calculated from the linkage value to Gpi-1 $=0.022$. The range covering its localization, assuming a $95 \%$ confidence limit, is indicated. The region of cyclin $E$ locus is marked in black. CE: centromere.

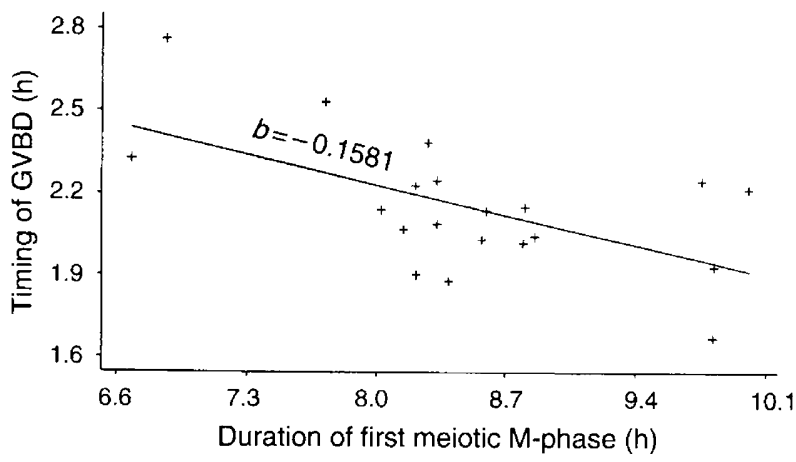

Fig. 2. Relationship between timing of germinal vesicle breakdown (GVBD) and the duration of the first meiotic M-phase. The duration of M-phase was calculated from data shown in Table 2. The regression coefficient $(b)$ is statistically significant $(P<0.01)$.

of first polar body extrusion. Correcting for the $95 \%$ confidence limit it should lie not closer than $0.05 \mathrm{cM}$ and not further than $19.6 \mathrm{cM}$ (Silver, 1985) from Gpi-1 (up and down). This delimits the segment of chromosome 7 of length $31.6 \mathrm{cM}$ beginning with the centromere, for the location of this gene (Fig. 1).

Two other loci on chromosome $7, c$ and $H b b$, were also available for analysis. The increasing number of RI strains that did not match with these loci (Gpi-1: 1/13; c: 6/13; Hbb: 7/13) reflects their order and distance on the chromosome; Gpi-1, $c$ and $H b b$ are mapped $12 \mathrm{Cm}, 42 \mathrm{Cm}$ and $50 \mathrm{Cm}$ from the centromere, respectively (Lyon and Kirby, 1996). The minimal linkage to $c$ and its lack to $H b b$ are in agreement with the proposed position of a putative gene close to Gpi-1.

For all other loci, except Gpi-1, the linkage, even when detected, was not significant.

The similar timing of GVBD in CBA and KE strains shows that the difference in the timing of first polar body extrusion between these strains refers to the period of maturation between GVBD and first polar body extrusion. Since upon GVBD the oocyte enters M-phase (Maro et al, 1994; Kishimoto, 1994), the difference between CBA and KE oocytes reflects the difference in the length of the first meiotic $M$-phase. The approximate length of first $\mathrm{M}$-phase among the tested strains was calculated by subtracting the mean time of GVBD from the mean time of first polar body extrusion. A negative correlation $(P<0.01)$ was found between the duration of these two steps of oocyte maturation. Generally, the more time is needed for GVBD the shorter is the duration of the M-phase and vice versa (Fig. 2).

\section{Discussion}

The rate of meiotic maturation was analysed in the present study by measuring the timing of GVBD and first polar body extrusion in maturing oocytes. It was found that, although the timing of GVBD did not differ between CBA and KE oocytes, it segregated between RI strains. This suggests that the timing of GVBD is polygenically determined and parental strains have different allele forms of genes involved. The number of loci responsible for this difference may be evaluated using the formula (Bailey, 1981):

$$
\text { minimum number of effective } \operatorname{loci}=\log (F+2) / \log 2
$$

where $F$ =number of recombinant strain phenotypes different from progenitor phenotypes (in this case $F=2$ ). According to such a calculation the parental strains differ for at least two loci the alleles of which probably act contrarily, hence CBA and KE mice are similar in timing of GVBD. The same conclusions may be drawn with respect to the observed variations in the efficiency of first polar body extrusion: for $F=3$ the minimum number of effective loci is also two, and $\mathrm{CBA}$ and $\mathrm{KE}$ strains are similar in efficiency of first polar body extrusion.

Considering the timing of the first meiotic division, it is concluded that the difference between parental strains also relates to at least two loci because some of the RI strains have an intermediate phenotype. However, it seems that these are different genes from those affecting the timing of GVBD in RI strains, because ( 1 ) the parental strains do not differ in the timing of GVBD (as in the case of first polar body extrusion) and (2) there is no positive correlation between the time needed for GVBD and the duration of the first meiotic M-phase among the lines tested. Involvement of different genes at these two steps of maturation accords with the present knowledge on the changes in activity of the maturation promoting factor (MPF), a universal factor controlling cell cycle progression (Murray, 1992). In maturing mouse oocytes this activity first appears around GVBD, increases as the oocyte enters first meiotic metaphase and then rapidly drops concomitant with first polar body extrusion (Hashimoto and Kishimoto, 1988; Choi et al., 1991; Kubiak et al., 1992). Moreover, initial growth of MPF activity, sufficient for GVBD, does not depend on protein synthesis, whereas its further increase requires synthesis of new protein(s) (Hashimoto and Kishimoto, 1988), most probably cyclin B (Hampl and Eppig, 1995). This finding suggests a different mechanism of control of MPF activity at transition from GV to GVBD and during M-phase.

The data presented in this study show a negative correlation between duration of GVBD and M-phase. A possible interpretation of this may be based on reports on the cooperation between nuclear and cytoplasmic factors of the cell cycle controlling mechanism. For example, CAK, a kinase responsible for MPF activation, has constant activity throughout the somatic cell cycle and its catalytic subunit $\mathrm{p} 40^{\mathrm{MO} 15}$ is localized in the nucleus at all stages except mitosis, when it redistributes throughout the cell (Tassan et al., 1994). The predominant localization of CAK in the GV as well as a similar lack of changes in activity have been demonstrated in Xenopus oocytes (Brown et al., 1995). Reciprocal fusion of nucleate and anucleate halves of oocytes from $\mathrm{CBA}$ and $\mathrm{KE}$ strains shows that the 
nucleus affects the timing of first polar body extrusion. Hybrids resulting from such fusions have the same cytoplasmic composition $(50 \% \mathrm{KE} / 50 \% \mathrm{CBA}$ ) but differ in the type of GV (CBA or $\mathrm{KE}$ ) and first polar body is extruded significantly earlier in those containing a $C B A$ nucleus $(Z$. Polański, N. J. Winston, M. H. Verlac, M. Weber, J. Z. Kubiak and B. Maro, unpublished). However, cytoplasm also contains an important factor(s): fusion of GV-containing fragment from KE oocytes with a cytoplasmic fragment obtained from CBA oocytes either equal in size or three times larger increased significantly and in a dose-dependent manner the rate at which the first polar body was extruded, compared with pure $\mathrm{KE}$ combination (Z. Polański, N. J. Winston, M. H. Verlac, M. Weber, J. Z. Kubiak and B. Maro, unpublished). These data suggest that a possible mechanism of regulation of $\mathrm{M}$-phase progression is a spatial separation of given factors into nuclear and cytoplasmic compartments during interphase and their interaction during $\mathrm{M}$-phase, after breakdown of the nuclear envelope. It is possible that these factors accumulate in the GV or cytoplasm (or in both compartments) just after resumption of meiotic maturation, and after GVBD cooperate in driving the M-phase. A good candidate would be, for example, cyclin B. It is intensively synthesized during the first meiotic M-phase of the mouse oocyte but an increase in both its quantity and its synthesis can be seen as early as during the first $2 \mathrm{~h}$ of maturation (Hampl and Eppig, 1995), whereas, in the same study, GVBD was observed after approximately $2 \mathrm{~h}$ of maturation. This raises the possibility that the triggering of cyclin B synthesis may precede the GVBD. Okumura et al. (1996) suggested that triggering the $M$-phase in starfish oocytes needs the participation of a process(es) independent of cdc2 kinase activation. Therefore, the possibility that triggering the cyclin B synthesis in mouse oocytes may be independent of and may precede MPF activation cannot be excluded. Because newly synthesized cyclin B is immediately complexed with p34 cdc2 (Hampl and Eppig, 1995), the amount of newly made inactive pre-MPF at the time of breakdown of the nucleus (when it becomes available for CAK) could, under these conditions, be relatively higher in oocytes in which GVBD occurred later.

One of the aims of this study was to search for the putative genes affecting the rate of the first meiosis of mouse oocytes. It seems that the most important genes in this respect may be those coding the proteins directly involved in cell cycle control, namely the cyclins and cyclin-dependent kinases (Pines, 1993), especially those implicated in M-phase regulation. The cyclin $\mathrm{E}$ locus $\left(\mathrm{C}_{\mathrm{Cne}}\right.$ ) has been detected in the mouse on chromosome 7 between D7Rp2 and Lhb/Klk1 (Johnson et al., 1996). According to the position of these loci (Lyon and Kirby, 1996), the cyclin E locus should be located about 15-17 cM from the centromere (Fig. 1). This is not only within the region delimited for the putative gene investigated in this study, but very close to one of its more probable positions in terms of its linkage to Gpi-1 (about $14 \mathrm{cM}$ from the centromere). It seems possible, therefore, that Cone may be one of the genes responsible for the differences in the duration of the first meiotic M-phase between KE and CBA oocytes. Cyclin E may be a component of cytostatic factor (CSF) (Rempel et al., 1995; Hartley et al., 1996). Cytostatic factor activity is responsible for metaphase II arrest in unfertilized eggs (Sagata et al., 1989;
Colledge et al., 1994; Hashimoto et al., 1994). However, it may also influence the timing of first meiosis, since in mouse oocytes lacking the primary component of CSF, the c-mos proto-oncogene product, the period of maturation between GVBD and first polar body extrusion is increased (Hashimoto et al., 1994) as in KE oocytes. We are in the process of using DNA probes, especially those specific for the region close to Cone as well as other regions not covered in this study, to broaden and verify the data presented here.

The author thanks $\mathrm{H}$. Krzanowska for helpful discussion and critical reading of the manuscript. This work was supported by grant from Polish Committee for Scientific Research (KBN; project number 4-1810-91-01) to H. Krzanowska.

\section{References}

Bailey DW (1971) Recombinant inbred strains Transplantation 11 325-327.

Bailey DW (1981) Recombinant inbred strains and bilineal congenic strains. In The Mouse in Biomedical Research pp 223-239 Eds HL. Foster, JD Small and JG Fox. Academic Press, New York

Braden AWH (1957) Variation between strains in the incidence of various abnormalities of egg maturation and fertilization in the mouse Journal of Genetics 55 476-486

Brown AJ, Jones T and Shuttleworth J (1995) Expression and activity of $\mathrm{p}^{4} 0^{\mathrm{MO} 15}$, the catalytic subunit of cdk-activating kinase, during Xenopus oogenesis and embryogenesis Molecular Biology of the Cell $5921-932$

Cho WK, Stern S and Biggers JD (1974) lnhibitory effect of dibutyryl cAMP on mouse oocyte maturation in vitro. Journal of Experimental Zoology 187 383-386

Choi T, Aoki F, Mori M, Yamashita M, Nagahama Y and Kohmoto K (1991) Activation of $\mathrm{p} 34^{\mathrm{cdc} 2}$ protein kinase activity in meiotic and mitotic cell cycles in mouse oocytes and embryos Development 113 789-795

Colledge WH, Carlton MB, Udy, GB and Evans MJ (1994) Disruption of c-mos causes parthenogenetic development of unfertilized mouse eggs Nature $\mathbf{3 7 0}$ $65-68$

Donahue RP (1968) Maturation of the mouse oocyte in vitro. I. Sequence and timing of nuclear progression Journal of Experimental Zoology 169 237-250

Fulton BP and Whittingham DG (1978) Activation of mammalian oocytes by intracellular injection of calcium Nature 273 149-151

Hampl A and Eppig JJ (1995) Translational regulation of the gradual increase in histone $\mathrm{HI}$ kinase activity in maturing mouse oocytes Molecular Reproduction and Development 40 9-15

Hartley RS, Rempel RE and Maller J (1996) In vivo regulation of the early embryonic cell cycle in Xenopus. Developmental Biology 173 408-419

Hashimoto N and Kishimoto T (1988) Regulation of meiotic metaphase by a cytoplasmic maturation-promoting factor during mouse oocyte maturation Developmental Biology 126 242-252

Hashimoto N, Watanabe N, Furuta Y, Tamemoto H, Sagata N, Yokoyama M, Okazaki K, Nagayoshi M, Takeda N, Ikawa Y and Aizawa S (1994) Parthenogenetic activation of oocytes in c-mos-deficient mice Nature 370 68-71

Johnson DK, Stubbs LJ and DeLoia JA (1996) The mouse cyclin E maps to Chromosome 7 Mammalian Genome 7245

Kaufman MH (1973) Parthenogenesis in the mouse Nature 242 475-476

Kishimoto T (1994) Cell reproduction: induction of M-phase events by cyclin-dependent cdc2 kinase International Journal of Developmental Biology 38 185-191

Krzanowska H, Polański Z, Wabik-Śliz B and Styrna J (1994) Research News Mouse Genome 92507

Kubiak JZ, Weber M, Geraud G and Maro B (1992) Cell cycle modification during the transition between meiotic M-phases in mouse oocytes Journal of Cell Science 102 457-467

Lyon MF and Kirby MC (1996) Mouse chromosome atlas Mouse Genome 94 29-73

Maro B, Kubiak JZ, Verlhac MH and Winston NJ (1994) Interplay between the cell cycle control machinery and the microtubule network in mouse oocytes Seminars in Developmental Biology 5 191-198

Murray AW (1992) Creative blocks: cell-cycle checkpoints and feedback controls Nature 359 599-604 
Okumura E, Sekiai T, Hisanaga S, Tachibana K and Kishimoto T (1996) Initial triggering of $\mathrm{M}$-phase in starfish oocytes: a possible novel component of maturation-promoting factor besides cdc2 kinase Journal of Cell Biology 132 125-135

Pines J (1993) Cyclins and cyclin-dependent kinases: take your partner Trends in Biochemical Sciences 18 195-197

Polański Z (1986) In vivo and in vitro maturation rate of oocytes from two strains of mice Journal of Reproduction and Fertility 78 103-109

Rafiński J, Styrna J and Krzanowska H (1991) Analysis of genetic markers in the recombinant inbred strains developed from $\mathrm{CBA} / \mathrm{KW}$ and $\mathrm{KE}$ mouse strains Zwierzeta Laboratoryjne 28 25-30

Rempel RE, Sleight SB and Maller J (1995) Maternal Xenopus Cdk2-cyclin E complexes function during meiotic and early embryonic cell cycles that lack a G1 phase Journal of Biological Chemistry 270 6843-6855
Sagata N, Watanabe N, Vande Woude GF and Ikawa Y (1989) The c-mos proto-oncogene product is a cytostatic factor responsible for meiotic arrest in vertebrate eggs Nalure $342512-518$

Silver J (1985) Confidence limits for estimates of gene linkage based on analysis of recombinant inbred strains journal of Heredity 76 436-440

Tarkowski AK (1971) Recent studies on parthenogenesis in the mouse Journal of Reproduction and Fertility Supplement 14 31-39

Tassan JP, Schultz SJ, Bartek J and Nigg EA (1994) Cell cycle analysis of the activity, subcellular localization, and subunit composition of human CAK (CDK-activating kinase) Journal of Cell Biology $127467-478$

Taylor BA (1981) Recombinant inbred strains. In Genetic Variants and Strains of the Laboratory Mouse pp 397-407 Ed. MC Green. Gustav Fischer Verlag, Stuttgart, New York 